\title{
Design of Heparin Oligosaccharide Based Molecules for Inhibition of Alzheimer Amyloid Beta (Aß40) Aggregation
}

\begin{tabular}{|r|l|}
\hline Journal: & Canadian Journal of Chemistry \\
\hline Manuscript ID & cjc-2016-0292.R1 \\
\hline Manuscript Type: & Article \\
\hline Complete List of Authors: & $\begin{array}{l}\text { Paul, Thomas ; University of Miami } \\
\text { Kelly, Harvey; University of Miami } \\
\text { Zuchniarz, Joshua; University of Miami } \\
\text { Ahmed, Tahir; Mount Sinai Medical Center } \\
\text { Prabhakar, Rajeev; University of Miami, }\end{array}$ \\
\hline Keyword: & $\begin{array}{l}\text { glycoaminoglycans, heparin disaccharide, amyloid fibril, amyloid beta, } \\
\text { Alzheimer's disease }\end{array}$ \\
\hline
\end{tabular}

SCHOLARONE ${ }^{1 m}$

Manuscripts 


\section{Amyloid Beta $\left(\mathbf{A} \beta_{40}\right)$ Aggregation}

Present Address:

${ }^{\dagger}$ Department of Chemistry, University of Miami, 1301 Memorial Drive, Coral Gables, FL 33146

${ }^{\S}$ Mount Sinai Medical Center, 4300 Alton Rd, Miami Beach, FL 33140

8

9

10

11

12

13

14

15

16

17

18

19

20 * To whom correspondence should be addressed; rpr@miami.edu; Tel: 305-284-9372;

21 Fax: 305-284-4571. 
23 Abstract. In this computational study, we have combined molecular docking and molecular

24 dynamics (MD) simulations techniques to explore interactions of monomeric and aggregated

25 forms of Alzheimer's amyloid beta $\left(\mathrm{A} \beta_{40}\right)$ with seven chemically distinct heparin derived

26 glycoaminoglycans (GAGs) referred to as ADC, SDC, DC, V1, V2, V3 and V4. The docking

27 procedure proposed two major binding sites, i.e one present at the top of the fibril (site A), and

28 the other located in the hairpin region (site B). Due to its position, site B offers an interesting

29 target to design molecules with anti-aggregation properties. Our results predicted that out of

30 seven GAGs, only three (ADC, SDC and DC) binds to site B. The identification of these

31 molecules can advance our efforts to develop therapeutic interventions for this deadly disease.

32

33 Keywords: glycoaminoglycans, heparin disaccharide, amyloid fibril, amyloid beta

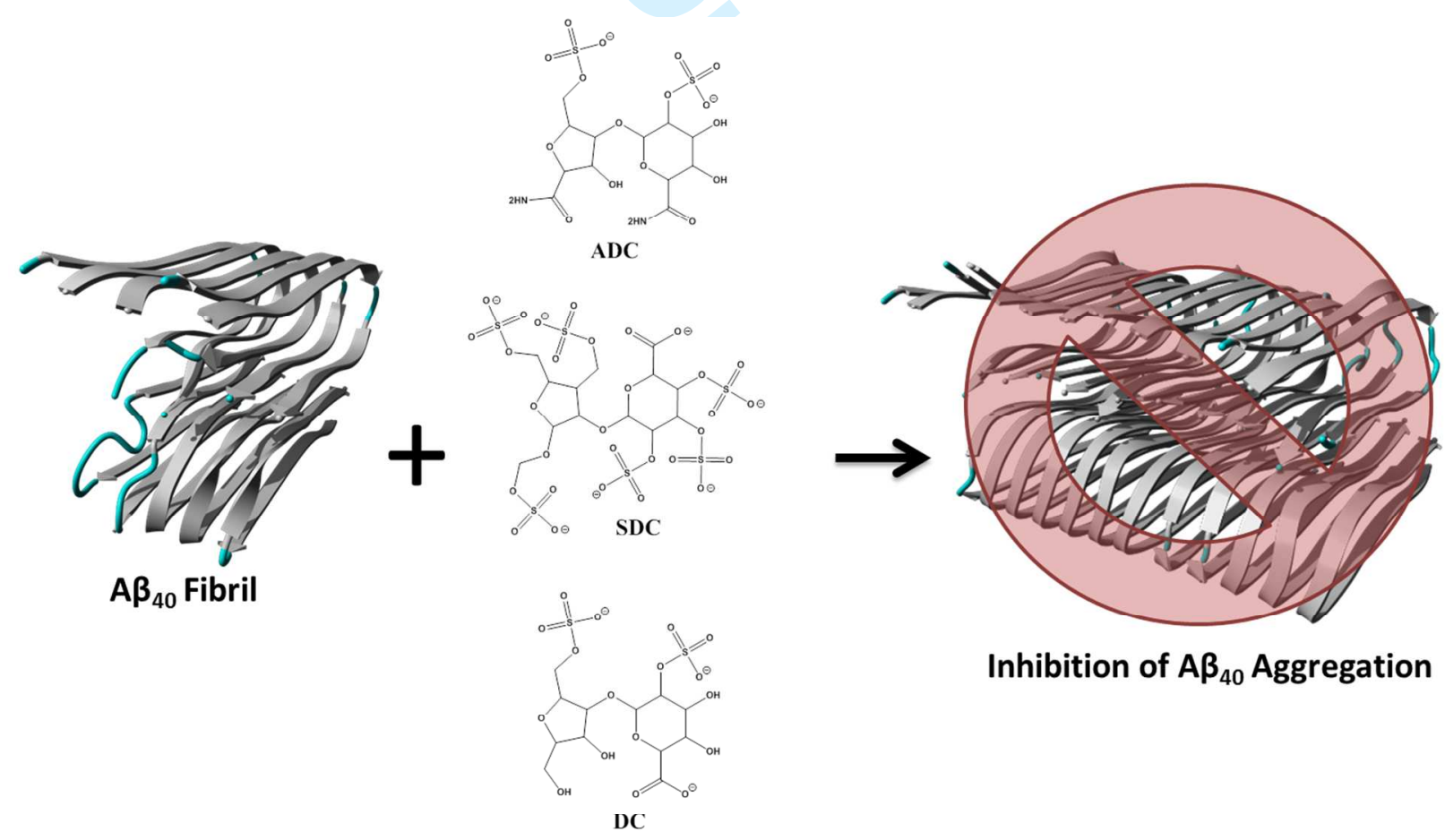




\section{Introduction.}

Alzheimer's disease $(\mathrm{AD})$ is a neurological disorder that affects more than 5 million Americans and is characterized by the accumulation of soluble and insoluble amyloid oligomers in the brain. ${ }^{1-2}$ The increasing number of people developing AD is placing a great strain on the

40 healthcare system. ${ }^{1-5}$ The major components of amyloid oligomers are individual amyloid beta

41 (A $\beta$ ) peptides consisting of 40-42 amino acids produced from the cleavage of the amyloid 42 precursor protein (APP). ${ }^{6-7}$ This process is catalyzed by two specialized enzymes, $\beta$-site APP43 cleaving enzyme-1 (BACE1) which cleaves the C-terminus fragment and $\gamma$-secretase which 44 subsequently cleaves the fragment produced by BACE1. ${ }^{8-10}$ After cleavage, the A $\beta 40-42$ 45 peptides tend to aggregate forming fibrils and later plaques within the brain. ${ }^{11}$ Therefore, one 46 main area of interest in treating $\mathrm{AD}$ is the development of therapeutic approaches; such as small

47 molecule inhibition ${ }^{12-15}$, that can decrease the $\mathrm{A} \beta$ aggregation in the brain. This task could be 48 accomplished by employing low molecular weight (LMW) glycoaminoglycans (GAGs) such as 49 enoxaparin, which has been shown to reduce $A \beta$ load within the brain. ${ }^{8,16-18}$ GAGs (examples 50 include hyaluronic acid, heparin, dermatan sulfate, heparan sulfate, and keratan sulfate), are

51 linear hetero-polysaccharides consisting of a hexosamine (e.g. hexuronic acid, L-iduronic acid, 52 galactose), disaccharide units, and sulfate substituents. ${ }^{19}$ The natural form of heparin, a linear 53 sulfated polysaccharide chain, can potentially disrupt the production of A $\beta$ peptides. ${ }^{11,20}$ GAGs

54 may regulate APP processing by $\beta$-secretase, but also might prevent the persistence of toxic 55 forms of $\mathrm{A} \beta$ oligomers by blocking the cell surface so repeating units cannot further 56 oligomerize. ${ }^{11,17}$

57 Within A $\beta 40-42$ peptides, charged amino acid residues between region 1-11 are critical 58 to $\mathrm{A} \beta$ pro-inflammatory response. ${ }^{11,21-23}$ Therefore, inhibiting the activity within this region 
59 could be useful in slowing the progress of AD. In binding to this site, heparin can prevent more 60 than $70 \%$ of A $\beta$ peptide binding to heparan sulfateproteoglycans (HSPG) and may also block cell 61 surface adhesion of $\mathrm{A} \beta$ monomer units. ${ }^{11,21,24-26}$ Both effects could protect neurons and vascular 62 endothelial cells against the toxic effects of $A \beta$ aggregation. ${ }^{11,21,25-26}$ It has also been 63 demonstrated that GAGs significantly attenuate the toxic effect of A $\beta$ on neuronal PC12 cells. ${ }^{27-}$

$64{ }^{29}$ In addition, GAG association with $\mathrm{A} \beta$ may prevent further aggregation or induce a different 65 kind of aggregation altogether. ${ }^{11,21,27}$ Furthermore, GAGs might cover the aggregate form of A $\beta$ 66 so that it cannot interact efficiently within cells to produce a toxic response. ${ }^{11,21,27-30}$ Heparin 67 and its sulfated forms are candidates for such a therapeutic activation. ${ }^{11,21,24-29}$ The development of heparin oligosaccharide analogs which can be used in the treatment

69 of $\mathrm{AD}$ will require several criteria to be met, such as; (1) the heparin oligosaccharide analogs 70 must be able to cross the blood-brain barrier, ${ }^{11,31-32}$ (2) possess high binding affinity for $A \beta$ 71 peptides $^{8}$ (3) and provide specificity for binding to only certain proteins within a cell line. ${ }^{8,31-32}$

72 In order to achieve this, structural information about the exact binding sites on either monomer 73 and/or fibril forms of $\mathrm{A} \beta 40-42$ peptides must be elucidated. It has been reported that the 74 specificity of haparan sulfate (HS) for binding to fibroblast growth factor receptors is controlled 75 primarily through its sulfation pattern. ${ }^{33-35}$ Furthermore, it is not well understood how the 76 number of sulfated groups present on the GAGs will affect their binding; therefore, fine tuning 77 the number of sulfated groups present could further provide specificity for binding. ${ }^{11,35}$ 78 Additionally, heparin derived hexa-sulfated disaccharide has been shown to inhibit allergic 79 inflammatory responses in the sheep model of allergic asthma for which a di-sulfated 80 disaccharide was ineffective, further supporting the role of increased sulfation. ${ }^{35}$ Given the wide 81 variety of GAGs which possess different molecular weights, charge densities, degree of 
82 sulfation, and types of saccharide units, the amount of possible motifs are enormous. ${ }^{11}$ However,

83 structures of $\mathrm{A} \beta$-GAGs complexes and information regarding the nature of interactions between

84 them are not available. In this study, we have combined molecular docking and molecular

85 simulations (MD) techniques to study interactions of both monomeric and fibrillar forms of $A \beta_{40}$

86 with a variety of chemically distinct GAG molecules (Figure 1). Our results will help to develop

87 novel LMW GAG compounds that could be used as a potential therapeutic option for the 88 treatment of AD.

90 II. Computational Details.

91 IIa. Computational models. All GAGs were modeled using the Gaussian 09 program package ${ }^{36}$

92 and optimized without any geometrical constraint. The $A \beta_{40}$ fibril structures were generously

93 provided by Robert Tycko using solid-state nuclear magnetic resonance (NMR) method (PDB ID:

$942 \mathrm{LMN}){ }^{37}$ The starting structure of the $\mathrm{A} \beta_{40}$ monomer was extracted from the NMR structures

95 determined in aqueous SDS micelles at $\mathrm{pH} 5.1$ (model 2, PDB ID: 1BA4). ${ }^{38}$ Both the A $\beta_{40}$

96 monomer and fibril structures were relaxed separately for 100 and 5 ns, respectively. Here, the

97 former was only partially relaxed by keeping every eighth alpha carbon frozen to retain its $\beta$ -

98 sheet rich structure. In the next step, to include flexibility into the docking procedure, 100

99 snapshots for the $\mathrm{A} \beta_{40}$ monomer and 5 for fibrils were taken at $1 \mathrm{~ns}$ intervals throughout the

100 simulations. These snapshots were used for the rigid docking of ADC (amide disaccharide), SDC

101 (super-sulfated disaccharide), and DC (heparin disaccharide) molecules using the YASARA ${ }^{39}$

102 software. This software employs the Vina scoring function and AutodockLGA (hybrid local

103 search genetic algorithm) that are also implemented in the Autodock Vina. ${ }^{40}$ Both Autodock

104 Vina and YASARA software have been used for docking in this study and were found to provide 
105 exactly the same results. In the docking procedure, the receptor was kept fixed, but the ligand 106 was allowed to change its conformation. Antechamber ${ }^{41-42}$ was used in order to parameterize the 107 ligands [ADC, SDC, DC, and its four variants (V1-V4)]. This step was performed in order to 108 accurately represent the sulfate groups during the docking and MD simulations.

109

110 IIb. Molecular docking. Molecular docking procedures were performed using YASARA ${ }^{39}$ 111 software to investigate the binding of the different forms of heparin to the $A \beta_{40}$ fibril and 112 monomer. The simulation cell chosen surrounded the whole ligand-protein/peptide complex, and 113 the spacing was kept to $1.00 \AA$. Further docking was performed with the simulation cell focused 114 on sites of interest (side binding sites) once they had been identified. Each docking trial produced 11520 poses implementing an exhaustiveness value equal to 20 .

117 IIc. MD simulations. The best 10 poses provided by the previous docking simulations were 118 further equilibrated for 10-20 ns to confirm the stability of binding sites. A cluster analysis of 119 these short simulations provided starting structures for the subsequent long range MD 120 simulations. The all-atom simulations of $\mathrm{ADC}, \mathrm{SDC}, \mathrm{DC}$, and all four variants with the $\mathrm{A} \beta_{40}$ 121 fibril were performed using GROMACS ${ }^{43}$ using the AMBER03 ${ }^{42}$ force field. Furthermore, MD 122 simulations were also performed on the ADC and SDC in complex with the $\mathrm{A} \beta_{40}$ monomer. For 123 all simulations, the starting structures were placed in a cubic box with dimensions of $80 \times 70 \times$ $12460 \AA$ for fibril and $40 \times 40 \times 40 \AA$ for the monomer simulations. The size of the box used in 125 these simulations was adequate and visualization of MD trajectories using the Visual Molecular 126 Dynamics (VMD) ${ }^{44}$ program did not show any interaction of the fibril and monomer with the 127 walls of the box. This eliminated unwanted effects that may have arisen from the applied 
128 periodic boundary conditions (PBC). ${ }^{45}$ The box was filled with single point charge (SPC) water

129 molecules. ${ }^{46}$ Some water molecules were replaced by sodium and chloride ions in order to

130 neutralize the system and simulate standard physiological conditions in mass percent of $0.9 \%$.

131 These structures were energy-minimized with a steepest descent method over 3000 steps. The

132 results of these minimizations produced the starting structures for the next round of MD

133 simulations. During both the energy minimization and MD simulations, every eighth alpha

134 carbon was frozen in order to maintain the structure of the fibril. Without these restraints, the

135 fibril structure became highly irregular and distorted. Each MD simulation was run for 100

136 nanoseconds. The simulations were carried out with a constant number of particles $(\mathrm{N})$, pressure

137 (P), and temperature (T) (NPT ensemble). The long-range electrostatic interactions were

138 calculated by the Particle-Mesh Ewald (PME) method. ${ }^{47}$ A constant pressure of 1 bar was

139 applied with a coupling constant of $1.0 \mathrm{ps}$; peptide, water molecules, and ions were coupled

140 separately to a bath at $298 \mathrm{~K}$ with a coupling constant of $0.1 \mathrm{ps}$. The equation of motion was

141 integrated at each 2 fs time steps. The tools available in the $\mathrm{VMD}^{44}$ program were utilized to

142 analyze the MD trajectories. The most representative structures were identified for structural

143 elucidation. The most representative structures were derived from a cluster analysis, where the

144 trajectories were analyzed by grouping structurally similar frames [root-mean-square deviation

145 (rmsd) cutoff of $0.30 \mathrm{~nm}$ ], while the frame with the largest number of neighbors was denoted as

146 a middle structure that represents that particular cluster. The computed root-mean-square-

147 deviations (rmsd) confirmed that all simulations attained equilibration within 50 or 100 ns for

148 monomers and fibrils, respectively (Figure S1-S3). The YASARA program ${ }^{39}$ was used for

149 molecular visualization throughout the study and for the preparation of structural diagrams. 
151 IId. Binding energy Calculations. The binding energy was computed using the following

152 equation:

$153 \Delta G_{\text {sol }}=\Delta G_{\text {Electrostatic binding }}+\Delta G_{\text {Nonpolar binding }}$

154 Where $\Delta G_{\text {Electrostatic binding }}$ and $\Delta G_{\text {Nonpolar binding }}$ represents the electrostatic and nonpolar 155 contributions to the solvation energy, respectively. A continuum electrostatic calculation was 156 performed to compute the electrostatic interaction between the GAGs (A) and the A $\beta_{40}$ 157 fibrils/monomers (B) utilizing the Adaptive Poisson-Boltzmann Solver (APBS) software. The 158 relative electrostatic binding energies were calculated using the following equation:

$159 \Delta G_{\text {Electrostatic binding }}=\Delta G_{\text {desol } A}^{\text {elec }}+\Delta G_{\text {desol } B}^{\text {elec }}+E_{A-B}^{\text {elec }}$

160 Where $E_{A-B}^{\text {elec }}$ is the electrostatic interaction energy between the GAGs and the $A \beta_{40}$ 161 fibrils/monomers when they were bound in solution. $E_{A-B}^{e l e c}$ was computed using the electrostatic 162 potential $\left(\psi_{\mathrm{i}}\right)$ generated by $\mathrm{A}$ at the position of the atomic charges $\left(\mathrm{q}_{\mathrm{i}}\right)$ of B by solving the 163 following equation:

$E_{A-B}^{e l e c}=\sum_{i}^{N} \varphi_{i} q_{i}$

$164 \Delta G_{\text {desol } A}^{\text {elec }}$ and $\Delta G_{\text {desol B }}^{\text {elec }}$ represent the electrostatic desolvation free energies of A (GAGs) and 165 B (fibrils/monomers), respectively, which are defined as the loss of the electrostatic interaction 166 between the A and B upon binding. The following two step approach was used to calculate this 167 energy: (1) calculation of the interaction energy of GAGs and the surrounding solvent in the 168 absence of the $A \beta_{40}$ fibrils/monomers and (2) calculation of the electrostatic energy of GAGs 169 with the surround solvent in the presence of the $A \beta_{40}$ fibrils/monomers. The differences in 170 energies calculated in these two steps provided the electrostatic desolvation energies $\Delta G_{\text {desol } A}^{\text {elec }}$ 171 or $\Delta G_{\text {desol } B}^{\text {elec }}$. 
172 The complexation between the GAGs and $A \beta_{40}$ fibrils/monomers was computed by solving the

173 Poisson-Boltzmann equation. These calculations were performed at room temperature using two

174 dielectric constants, 2.0 and 78.0 that represent protein and water environments, respectively. A

175 probe sphere of $1.5 \AA$ was used for the calculation of the solute surface, and grid spacing was

176 kept to $0.35 \AA$. The dielectric boundary was defined as the van der Waals surface and a salt

177 concentration of $55 \mathrm{mM}$ was used. For all these calculations, all clustered structures in the PDB

178 format were converted to the PQR format using the PDB2PQR server. The charges of GAGs

179 were calculated based on initial resp charges calculated using quantum mechanical methods

180 (Gaussian 09). The nonpolar contribution to the free energy was computed from the burial of

181 solvent accessible surface area (SASA) of the GAGs and the $\mathrm{A} \beta_{40}$ fibrils/monomers upon

182 binding using the following equation.

$183 \Delta G_{\text {Nonpolar binding }}=\gamma \times S A S A$

184 Where SASA values of the individual components GAGs and $A \beta_{40}$ fibrils/monomers, as well as, 185 complexations were calculated utilizing the YASARA program. The microscopic surface tension 186 coefficient $\left(\gamma=0.0054 \mathrm{kcal} / \mathrm{mol} \AA^{2}\right)$ connects the solvent accessible surface area to the free 187 energy of transferring a molecule from alkane to water.

189 III. Results and Discussion.

190 IIIa. Docking of ADC, SDC, and DC to A $\boldsymbol{\beta}_{\mathbf{4 0}}$. Docking of ADC, SDC, and DC to the A $\beta 40$

191 fibril showed two major binding sites (A and B in Figure 2). The sites A and B are located in two 192 distinct H14-K16 and E22-K28 regions, respectively. The site A runs longitudinally to the fibril 193 axis and its number would increase with the growth of fibril. It is formed by residues H14, Q15, 194 and K16 that are located on the top of the fibril. This binding site was generated by the 
195 interactions between the negatively charged sulfates attached to ADC, SDC, and DC and the 196 positively charged amino acid residues on the fibril's surface. For instance, the carboxylate and 197 sulfate groups of both ADC and SDC formed hydrogen bonds with H14 and K16 residues of the $198 \mathrm{~A} \beta_{40}$ fibril. DC showed similar hydrogen bonding interactions with three K16 residues of the 199 fibril. On the other hand, the second site (site B) located at the terminal of the A $\beta$ fibrils within 200 the hairpin region is scarce considering the direction of the fibril elongation. It is generated by 201 residues E22, D23, V24, G25, S26, N27, and K28 in the E22-K28 region of the fibril. Due to its 202 location, binding to this site has the potential to inhibit the aggregation of $\mathrm{A} \beta$ fibrils; therefore, 203 this binding site has been specifically focused on in our studies. ${ }^{13}$ The ADC, SDC, and DC 204 molecules were also found to bind to the site B. Furthermore, ADC, SDC, and DC were docked 205 to the $A \beta_{40}$ monomer in order to elucidate the possible binding interactions between the earliest 206 stage of $\mathrm{A} \beta_{40}$ aggregation and our heparin analogues. All three analogues studied bind to the N207 terminus region of the peptide and strongly interact with polar amino acid R5, as well as, neutral 208 residue $\mathrm{H6}$.

210 IIIb. A $\boldsymbol{\beta}_{40}-\mathbf{A D C}$ interactions. The ADC molecule shows binding to the N-terminus region of 211 the $\mathrm{A} \beta_{40}$ monomer (Figure 3), between residues $\mathrm{A} 1$ and H6. Strong electrostatic interactions 212 between the sulfated group present on ADC and polar residues D1 and R5 at distances of 2.13 213 and $1.97 \AA$ respectively were observed. Furthermore, H6 shows a hydrogen bonding interaction 214 with the terminal amine of ADC at a distance of $1.77 \AA$. The binding energy computed for this 215 complex was $-18.4 \mathrm{~kJ} / \mathrm{mol}$ (Table 1 ).

216 MD simulations were also run with $\mathrm{ADC}$ binding to both $\mathrm{A}$ and $\mathrm{B}$ sites of the $\mathrm{A} \beta_{40}$ fibril

217 (Figure 4). Site A was stabilized by many hydrogen bonds originating from polar and charged 
218 amino acid residues H14 and K16, respectively. Moreover, ADC interacts through a host of

219 hydrogen bonding interactions with polar residues located at site B (E22-K28) of the A $\beta_{40}$ fibril.

220 The amine present on ADC displays strong hydrogen bonding with a negatively charged oxygen

221 of E22 at a distance of $2.23 \AA$. Additionally, ADC interacts with multiple K28 residues on

222 separate monomers within the fibril through hydrogen bonding at distances shorter than $2.5 \AA$.

223 The binding energy calculated for this complex was $-22.4 \mathrm{~kJ} / \mathrm{mol}$ (Table 1), which is more

224 negative when compared to the binding of ADC to the peptide form.

226 IIIc. A $\boldsymbol{\beta}_{40}$ - SDC interactions. The supersulfated form (SDC) of the heparin disaccharide

227 interacts with the $A \beta_{40}$ monomer through its $\mathrm{N}$-terminus region. The SDC is stabilized within this

228 pocket by three electrostatic interactions with the N-terminus of residue D1 at distances of 2.06,

$2292.35,3.32 \AA$ (Figure 5). Positive residue R5 also shows two strong hydrogen bonds with a sulfate

230 group of SDC at distances of 2.30 and $2.44 \AA$. These strong interactions kept SDC in place over

231 the course of the MD simulation. The binding energy calculated for this complex indicates stable

232 binding energies within this site $(-20.2 \mathrm{~kJ} / \mathrm{mol}$, Table 1$)$. This is slightly better than the previous

233 case with ADC. However, this trend was expected due to an increase in negative charge for the

234 SDC with compared with the ADC (more sulfate groups were added). This increase in negative

235 charge would increase the attraction between SDC and the positively charged residues present on

236 the $\mathrm{A} \beta_{40}$ aggregate's surface. SDC also interacted strongly with both site $\mathrm{A}$ and $\mathrm{B}$ of the fibril

237 (Figure 6). MD simulations of site A reveal a host of hydrogen bonding interactions originating

238 from polar and charged amino acid residues $\mathrm{H} 14$ and K16, respectively. All hydrogen bonds are

239 within $3.0 \AA$, which indicates strong hydrogen bonding between the fibril's surface and the

240 sulfate groups present on SDC. Interestingly, only three of the six sulfate groups interact with the 
241 fibrils surface, most likely due to steric clashes or strain and electrostatic repulsion that would 242 arise from the charged groups being too close together. For site B, again there were multiple

243 hydrogen bonding interactions that were responsible for the binding of the ligand to the fibril.

244 One sulfate group exhibited hydrogen bonding with N27 and K28. Another sulfate group

245 interacted with V24 and the K28 of the neighboring monomer at distances of 1.84 and 2.01,

246 respectively. The carboxylate group present on SDC also interacted with K28 at a distance of

$2472.12 \AA$. The binding energy calculated for this complex indicates stable binding energies within

248 this site $(-28.8 \mathrm{~kJ} / \mathrm{mol}$, Table 1$)$. Since inhibition of the generation of higher order $\mathrm{A} \beta_{40}$

249 oligomers has been proposed as one of the promising strategies to prevent AD, the interactions of

250 only the fibril form have been investigated with the remaining GAG molecules.

252 IIId. $\mathbf{A} \boldsymbol{\beta}_{40}-$ DC interactions. At site $A$, the side chain of $\mathrm{K} 16$ of $A \beta_{40}$ interacted with the

253 negatively charged oxygen located within a sulfate group of DC. Only one sulfate group present

254 on DC was not interacting with the fibril. The binding pocket was further stabilized by H14,

255 showing a strong hydrogen bond with a sulfate group at a distance of $1.958 \AA$. Furthermore,

256 down the fibril, K16 associated with a hydroxyl present on the ring of the heparin analogue. In

257 many of our simulations, binding to different sections of the fibril caused the DC molecule to

258 move to the top binding site. However, the association with site B of the fibril remained intact

259 throughout the simulation time. At this site, DC exhibited several hydrogen bonding interactions

260 as detailed in Figure 7. One of the sulfate groups of DC interacted with V24 and S26 residues in

261 the hairpin region at distances of 1.80 and $2.00 \AA$, respectively. Additional interactions included

262 hydrogen bonding between the carboxylate group of DC and a K28 residue and between a 263 hydroxyl group of DC and another K28 residue. These strong hydrogen bonding interactions 
264 were sufficient to keep DC bound to the fibril as seen over the course of a MD simulation. DC

265 shows the weakest binding energy when comparing the three molecules studied, but was

266 expected. With increasing negative charge present within the heparin analogues the binding

267 energy also increases, this is not surprising as the negative charges of the heparin analogues

268 would be attracted to the positively charged residues on the aggregates surface, whether on the

269 side or top of the fibril. However, binding to the side of the fibrils surface would block the

270 addition of more peptide units thereby controlling the aggregation of these critical peptides.

272 IIIe. $\mathbf{A} \boldsymbol{\beta}_{40}-$ DC variants (V1, V2, V3 and V4) interactions. In addition to the three models

273 described ADC, SDC, and DC, four more analogues were studied to see the effect of modifying

274 the functional group present within our standard DC molecule. These four analogues are shown

275 in Figure 1. In the first variant studied (V1), both the hydroxyl and carboxyl groups were

276 deprotonated. The main reasons for the changes were to allow for more hydrogen bonding

277 acceptors on the surface of V1 to increase the interaction with site $\mathrm{B}$ of the $\mathrm{A} \beta_{40}$ fibril.

278 Furthermore, the deprotonated carboxylic acid could function as a molecular hook allowing for

279 hydrogen bonding interactions at either end of their functional groups. However, V1 only

280 interacted with site A and would not bind to site B of the fibril. In the second variant (V2), one

281 carboxylic acid group was substituted for an aromatic benzene ring to see if the addition of a

282 hydrophobic group would help stabilize site B. This site could be stabilized by interacting with

283 some of the hydrophobic residues hidden within the stacks of the $A \beta_{40}$ fibrils. However, no

284 binding to this site of the fibrils was observed, mostly due to the steric bulkiness of the benzene

285 group present on V2. In all of the simulations, V2 failed to stay bound to site B but did bind to a

286 new pocket. Interestingly, V2 shifts to a more hydrophobic site on the top of the fibril closer to 
287 hydrophobic residues V18 and F19. In the third variant (V3), the aromatic benzene was kept and 288 a carboxylic acid group substituted for an amide group. Again, due to the bulkiness of the 289 benzene ring, V3 binds only to the hydrophobic site formed by residues K16-F19. In the last

290 Variant studied V4, methoxy groups were added to the DC fame work to gain the hydrophobic 291 binding benefit but lose the steric bulkiness of having a benzene ring. Again, as seen for V3, V4 292 binds to the hydrophobic site formed between residues K16-F19 and did not bind to site B of the $293 \mathrm{~A} \beta_{40}$ fibril.

295 IV. Conclusions. In this study, we have employed molecular docking and MD simulations 296 techniques to investigate interactions of both monomeric and aggregated forms of $\mathrm{A} \beta_{40}$ with a 297 wide range of chemically diverse forms of GAGs referred to as ADC, SDC, DC, V1, V2, V3 and 298 V4 (Figure 1). GAGs such as heparin have been experimentally proposed to inhibit the 299 generation of neurotoxic forms of amyloid oligomers. ${ }^{18,48-49}$ Our docking results predicted two 300 major binding sites (A and $B$ ) on $A \beta_{40}$ fibrils (Figure 2). Site $A$ is located at the top of the fibril, 301 while site B is present in the hairpin region. Since the latter lies along the axis of fibrils, it is a 302 novel target to design molecules to inhibit $A \beta$ aggregation. ${ }^{13}$

304 The binding of ADC and SDC was investigated with both monomeric and fibrillar forms of $305 \mathrm{~A} \beta_{40}$, while the interactions of the remaining GAGs were studied only with the former. Both $306 \mathrm{ADC}$ and SDC interacted with N-terminus, D1-H6 region, of the $\mathrm{A} \beta_{40}$ monomer (Figure 3 and 307 5). On the other hand, $\mathrm{ADC}, \mathrm{SDC}$, and $\mathrm{DC}$ associated with both $\mathrm{A}$ and $\mathrm{B}$ sites of the $\mathrm{A} \beta_{40}$ fibril 308 in the H14-K16 and E22-K28 regions, respectively (Figure 4, 6 and 7). Among the four 309 analogues of DC, V1 interacted only with site A and V2, V3 and V4 bound to neither site (Table 
310 2). These results suggested that ADC, SDC and DC can inhibit amyloid aggregation and lead to

311 the development of molecules for the prevention of AD.

312

313 V. Acknowledgements. Financial support from the James and Esther King Biomedical Research

314 Program of the Florida State Health Department (DOH grant number 08KN-11) to R.P. is greatly

315 acknowledged. Computational resources from the Center for Computational Science (CCS) at

316 the University of Miami are greatly appreciated. This article is submitted in honor of Professors

317 Russell Boyd and Arvi Rauk.

318

319 VI. Supporting Information Material (SI). Figure S1-S3: The figures showing the computed

320 root-mean-square-deviations (rmsd). 
334 1. Gaugler, J.; James, B.; Johnson, T.; Scholz, K.; Weuve, J., Alzheimer's and Dementia 2014, 33510.

336 2. Wahlster, P.; Niederländer, C.; Kriza, C.; Schaller, S.; Kolominsky-Rabas, P. L., Dement.

337 Geriatr. Cogn. Disord. 2013, 36, 263.

338 3. Ryan, S. M.; Kelly, Á. M., Ageing Res. Rev. 2016, 27, 77. doi: 10.1016/j.arr.2016.03.007.

339 4. Neumann, U.; Rueeger, H.; Machauer, R.; Veenstra, S. J.; Lueoend, R. M.; Tintelnot-

340 Blomley, M.; Laue, G.; Beltz, K.; Vogg, B.; Schmid, P.; Frieauff, W.; Shimshek, D. R.;

341 Staufenbiel, M.; Jacobson, L. H., Mol. Neurodegener. 2015, 10, 44. doi: 10.1186/s13024-015-

$342 \quad 0033-8$

343 5. Santana-Blank, L.; Rodríguez-Santana, E.; Santana-Rodríguez, K. E.; Reyes, H., Photomed.

344 Laser Surg. 2016, 34, 93. doi: 10.1089/pho.2015.4015.

345 6. Masters, C.; Simms, G.; Weinman, N., Proc. Natl. Acad. Sci. U.S.A. 1985, 4245.

346 7. Glenner, G.; Wong, C., Biochem. Biophys. Res. Commun. 1984, 120. doi: 10.1016/S0006-

$347 \quad 291 X(84) 80190-4$.

348 8. Cui, H.; Hung, A.; Freeman, C.; Small, D., J. Neurochem. 2012, 447. doi: 10.1111/j.1471-

349 4159.2012.07929.x.

350 9. Grimm, M. O. W.; Mett, J.; Stahlmann, C. P.; Grösgen, S.; Haupenthal, V. J.; Blümel, T.;

351 Hundsdörfer, B.; Zimmer, V. C.; Mylonas, N. T.; Tanila, H.; Müller, U.; Grimm, H. S.;

352 Hartmann, T., Front. Aging Neurosci. 2015, 7, 77. doi: 10.3389/fnagi.2015.00077.

353 10. Cappai, R., J. Neurochem. 2016. doi: 10.1111/jnc.13546.

354 11. Bergamaschini, L.; Rossi, E.; Vergani, C.; Simoni, M. D., Scientific World J. 2009, 891. 
355 12. Derrick, J. S.; Kerr, R. A.; Nam, Y.; Oh, S. B.; Lee, H. J.; Earnest, K. G.; Suh, N.; Peck, K.

356 L.; Ozbil, M.; Korshavn, K. J.; Ramamoorthy, A.; Prabhakar, R.; Merino, E. J.; Shearer, J.; Lee,

357 J.-Y.; Ruotolo, B. T.; Lim, M. H., J. Am. Chem. Soc. 2015, 137, 14785. doi:

$358 \quad 10.1021 /$ jacs.5b10043.

359 13. Cook, N. P.; Ozbil, M.; Katsampes, C.; Prabhakar, R.; Martí, A. A., J. Am. Chem. Soc. 2013, 360 135, 10810. doi: 10.1021/ja404850u.

361 14. Prabhakar, R., Future Med. Chem. 2009, 1, 119. doi: 10.4155/fmc.09.10.

362 15. Echeverria, V.; Zeitlin, R.; Burgess, S.; Patel, S.; Barman, A.; Thakur, G.; Mamcarz, M.;

363 Wang, L.; Sattelle, D. B.; Kirschner, D. A.; Mori, T.; Leblanc, R. M.; Prabhakar, R.; Arendash,

364 G. W., J. Alzheimers Dis. 2011, 24, 817. doi: 10.3233/JAD-2011-102136.

365 16. Cui, H.; Hung, A. C.; Klaver, D. W.; Suzuki, T.; Freeman, C.; Narkowicz, C.; Jacobson, G.

366 A.; Small, D. H., PLoS ONE 2011, 6, e23007. doi: 10.1371/journal.pone.0023007.

367 17. Timmer, N. M.; van Dijk, L.; der Zee, C. E. E. M. v.; Kiliaan, A.; de Waal, R. M. W.;

368 Verbeek, M. M., Neurobiol. Dis. 2010, 40, 340. doi: 10.1016/j.nbd.2010.06.008.

369 18. Bergamaschini, L.; Rossi, E.; Storini, C.; Pizzimenti, S.; Distaso, M.; Perego, C.; De Luigi,

370 A.; Vergani, C.; Grazia De Simoni, M., J. Neurosci. 2004, 24, 4181. doi:

371 10.1523/jneurosci.0550-04.2004.

372 19. Hanin, I.; Dudas, B.; Mervis, R. F.; Cornelli, U.; Lee, J. M.; Lorens, S. A.; Fareed, J. In

373 Mapping the Progress of Alzheimer's and Parkinson's Disease; Mizuno, Y.; Fisher, A.; Hanin,

374 I., Eds. Springer US: Boston, MA, 2002; 171.

375 20. Sain, M.; Kovacic, V.; Radic, J.; Ljutic, D.; Jelicic, I., Drug \& Aging 2012, 29, 1. doi:

$376 \quad 10.2165 / 11592870-000000000-00000$. 
377 21. Bergamaschini, L.; Donarini, C.; Gobbo, G.; Parnetti, G., Mech. Ageing Dev. 2001, 1971.

378 doi: 10.1016/S0047-6374(01)00311-6.

379 22. Velazquez, P.; Cribbs, D. H.; Poulos, T. L.; Tenner, A. J., Nat. Med. 1997, 3, 077. doi:

$380 \quad 10.1038 / \mathrm{nm} 0197-77$.

381 23. Webster, S.; Bonnell, B.; Rogers, J., Am. J. Pathol. 1997, 1531.

382 24. Ma, Q.; Cornelli, U.; Hanin, I.; Jeske, W.; Linhardt, R., Curr. Pharm. Des. 2007, 1607.

383 25. Tyrrell, D.; Horne, A.; Preuss, K.; Page, C., Adv. Pharmacol. 1999, 151.

384 26. Watson, D.; Lander, A.; Selkoe, D., J. Biol. Chem. 1997, 31617. doi:

$385 \quad 10.1074 / \mathrm{jbc} .272 .50 .31617$.

386 27. Bergamaschini, L.; Donarini, C.; Rossi, E.; Luigi, A. D.; Vergani, C., Neurobiol. Aging.

387 2002, 531. doi: 10.1016/S0197-4580(02)00003-9.

388 28. Pollack, S.; Sanders, I.; Hawtin, S., Neurosci. Lett. 1995, 211. doi: 10.1016/0304-

389 3940(95)11939-T.

390 29. Pollack, S.; Sanders, I.; Hawtin, S., Neurosci. Lett. 1995, 113. doi: 10.1016/0304-

$3913940(94) 11182-\mathrm{I}$.

392 30. Woods, A.; Cribbs, D.; Whittemore, E.; Cotman, C., Brain Res. 1995, 53. doi:

393 10.1016/0006-8993(95)00775-L.

394 31. Leveugle, B.; Ding, W.; Laurence, F.; Dehouck, M.; Scanameo, A.; Cecchelli, R.; Fillit, H., 395 J. Neurochem. 1998, 736. doi: 10.1046/j.1471-4159.1998.70020736.x.

396 32. Leveugle, B.; Ding, W.; Durkin, J.; Mistretta, S.; Eisle, J.; Matic, M.; Siman, R.; Greenberg, 397 B.; Fillit, H., Neurochem. Int. 1997, 543. doi: 10.1016/S0197-0186(96)00103-9.

398 33. Nurcombe, V.; Ford, M.; Wildschut, J.; Bartlett, P., Science 1993, 260, 103. doi:

$399 \quad 10.1126 /$ science.7682010. 
34. Zhu, H.; Yu, J.; Kindy, M. S., Mol. Med. 2001, 7, 517.

401 35. Ahmed, T.; Smith, G.; Abraham, W. M., Pulm. Pharmacol. Ther. 2014, 28, 77. doi:

$402 \quad 10.1016 /$ j.pupt.2013.12.001.

403 36. Frisch, M. J.; Trucks, G. W.; Schlegel, H. B.; Scuseria, G. E.; Robb, M. A.; Cheeseman, J.

404 R.; Scalmani, G.; Barone, V.; Mennucci, B.; Petersson, G. A.; Nakatsuji, H.; Caricato, M.; Li, 405 X.; Hratchian, H. P.; Izmaylov, A. F.; Bloino, J.; Zheng, G.; Sonnenberg, J. L.; Hada, M.; Ehara, 406 M.; Toyota, K.; Fukuda, R.; Hasegawa, J.; Ishida, M.; Nakajima, T.; Honda, Y.; Kitao, O.;

407 Nakai, H.; Vreven, T.; Montgomery Jr., J. A.; Peralta, J. E.; Ogliaro, F.; Bearpark, M. J.; Heyd, 408 J.; Brothers, E. N.; Kudin, K. N.; Staroverov, V. N.; Kobayashi, R.; Normand, J.; Raghavachari, 409 K.; Rendell, A. P.; Burant, J. C.; Iyengar, S. S.; Tomasi, J.; Cossi, M.; Rega, N.; Millam, N. J.; 410 Klene, M.; Knox, J. E.; Cross, J. B.; Bakken, V.; Adamo, C.; Jaramillo, J.; Gomperts, R.;

411 Stratmann, R. E.; Yazyev, O.; Austin, A. J.; Cammi, R.; Pomelli, C.; Ochterski, J. W.; Martin, R. 412 L.; Morokuma, K.; Zakrzewski, V. G.; Voth, G. A.; Salvador, P.; Dannenberg, J. J.; Dapprich, 413 S.; Daniels, A. D.; Farkas, Ö.; Foresman, J. B.; Ortiz, J. V.; Cioslowski, J.; Fox, D. J. Gaussian 414 09, Gaussian, Inc.: Wallingford, CT, USA, 2009.

415 37. Petkova, A. T.; Yau, W. M.; Tycko, R., Biochemistry 2006, 45, 498. doi:

$41610.1021 /$ bi051952q.

417 38. Coles, M.; Bicknell, W.; Watson, A. A.; Fairlie, D. P.; Craik, D. J., Biochemistry 1998, 37, 418 11064. doi: 10.1021/bi972979f.

419 39. Krieger, E.; Vriend, G., Bioinformatics 2002, 18, 315.

420 40. Trott, O.; Olson, A. J., J. Comput. Chem. 2010, 31, 455. doi: 10.1002/jcc.21334.

421 41. Wang, J.; Wang, W.; Kollman, P. A.; Case, D. A., J. Mol. Graph. Model. 2006, 25, 247. doi: $422 \quad 10.1016 /$ j.jmgm.2005.12.005. 
423 42. Wang, J.; Wolf, R. M.; Caldwell, J. W.; Kollman, P. A.; Case, D. A., J. Comput. Chem.

424 2004, 25, 1157. doi: 10.1002/jcc.20035.

425 43. Lindahl, E.; Hess, B.; van der Spoel, D., J. Mol. Model. 2001, 7, 306. doi:

$42610.1007 / \mathrm{s} 008940100045$.

427 44. Humphrey, W.; Dalke, A.; Schulten, K., J. Mol. Graph. 1996, 14, 33. doi: 10.1016/0263$428 \quad 7855(96) 00018-5$.

429 45. Makov, G.; Payne, M. C., Phys. Rev. B. 1995, 51, 4014. doi: 10.1103/PhysRevB.51.4014.

430 46. Berendsen, H. J. C.; Postma, J. P. M.; van Gunsteren, W. F.; Hermans, J. In Intermolecular

431 Forces: Proceedings of the Fourteenth Jerusalem Symposium on Quantum Chemistry and

432 Biochemistry Held in Jerusalem, Israel, April 13-16, 1981; Pullman, B., Ed. Springer

433 Netherlands: Dordrecht, 1981; 331.

434 47. Darden, T.; York, D.; Pedersen, L., J. Chem. Phys 1993, 98, 10089. doi:

435 doi:10.1063/1.464397.

436 48. Leveugle, B.; Ding, W.; Laurence, F.; Dehouck, M.-P.; Scanameo, A.; Cecchelli, R.; Fillit,

437 H., J. Neurochem. 1998, 70, 736. doi: 10.1046/j.1471-4159.1998.70020736.x.

438 49. Walzer, M.; Lorens, S.; Hejna, M.; Fareed, J.; Hanin, I.; Cornelli, U.; Lee, J. M., Eur. J.

439 Pharmacol. 2002, 445, 211. doi: 10.1016/S0014-2999(02)01759-4. 


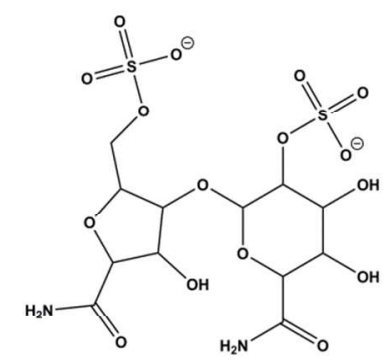

ADC

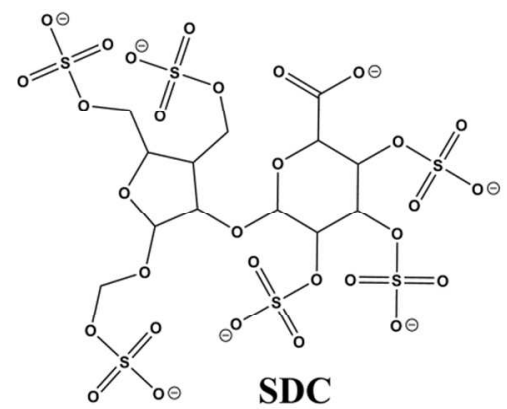

SDC

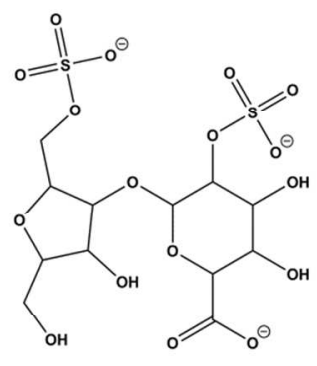

DC<smiles>O=C(O)C1OC(OC2C(=O)C(C(=O)O)OC2COS(=O)(=O)O)C(OS(=O)(=O)O)C(=O)C1=O</smiles>

V1<smiles>O=C(O)C1OC(COP(=O)(=O)([O-])O)C(OC2OC(c3ccccc3)[C@H](O)[C@H](O)C2O)C1OS(=O)(=O)O</smiles>

V2

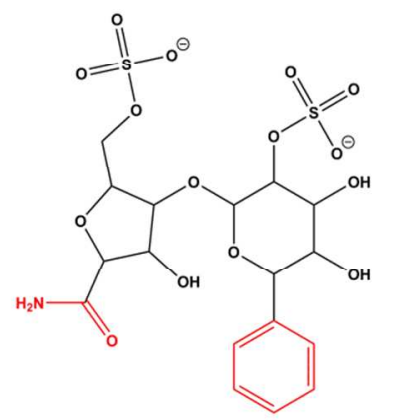

V3

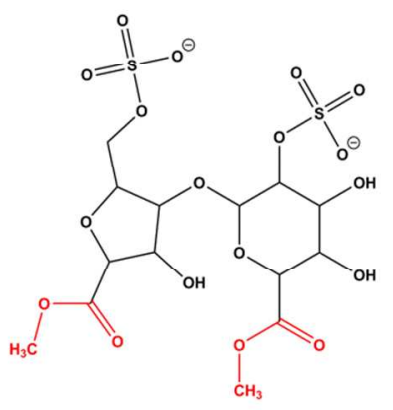

V4

441 Figure 1. Atomic representation of heparin analogues used within this study. ADC (amide

442 disaccharide), SDC (super-sulfated disaccharide), DC (heparin disaccharide), and structural

443 models of DC variants (V1, V2, V3 and V4) are shown. Functional group substitutions are 444 shown in red compared to DC. 


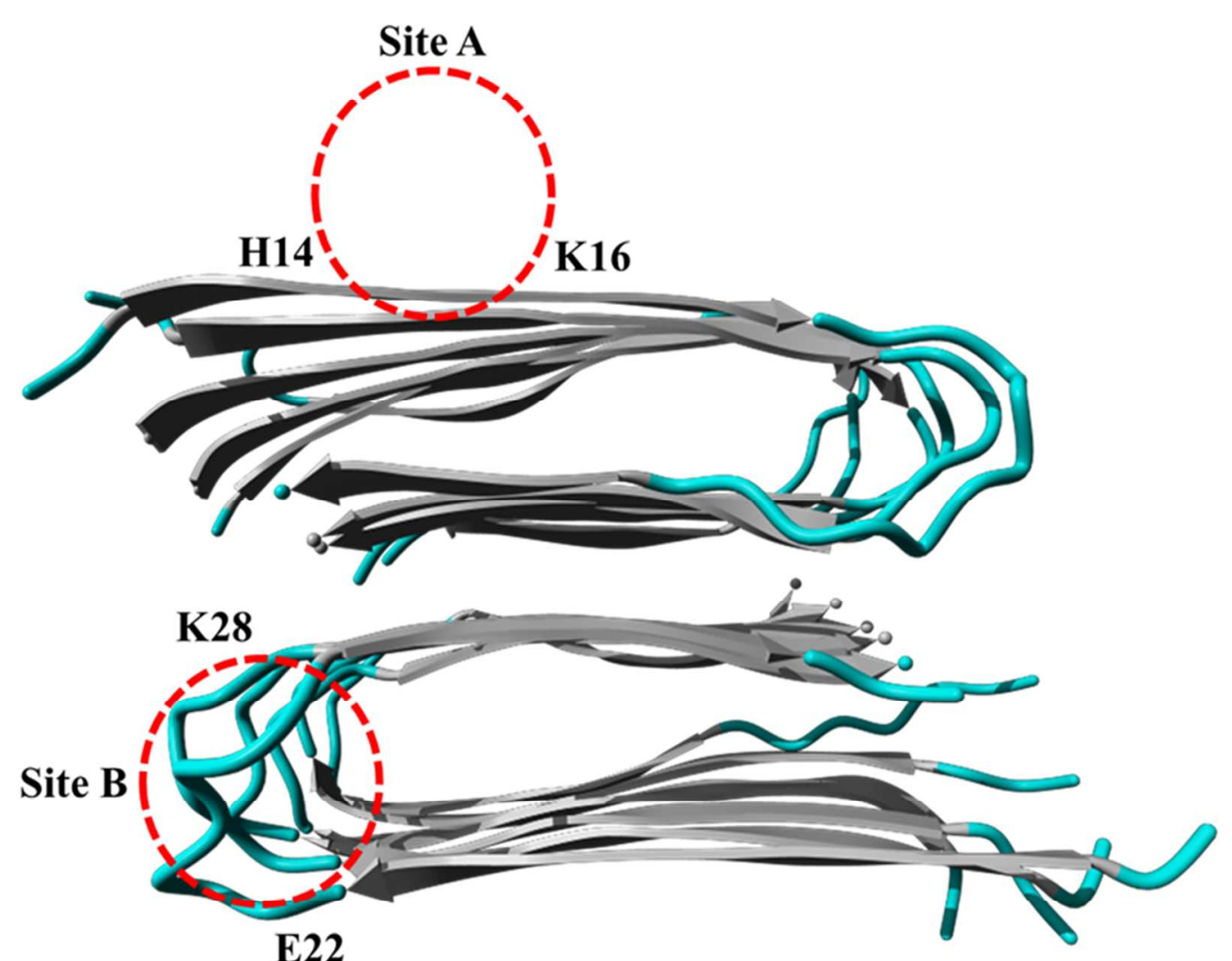

455 Figure 2. $\mathrm{A} \beta_{40}$ fibril structure. Binding site $\mathrm{A}$ is formed between residues H14 and K16. Binding 456 site B is formed between residues E22 and K28. 

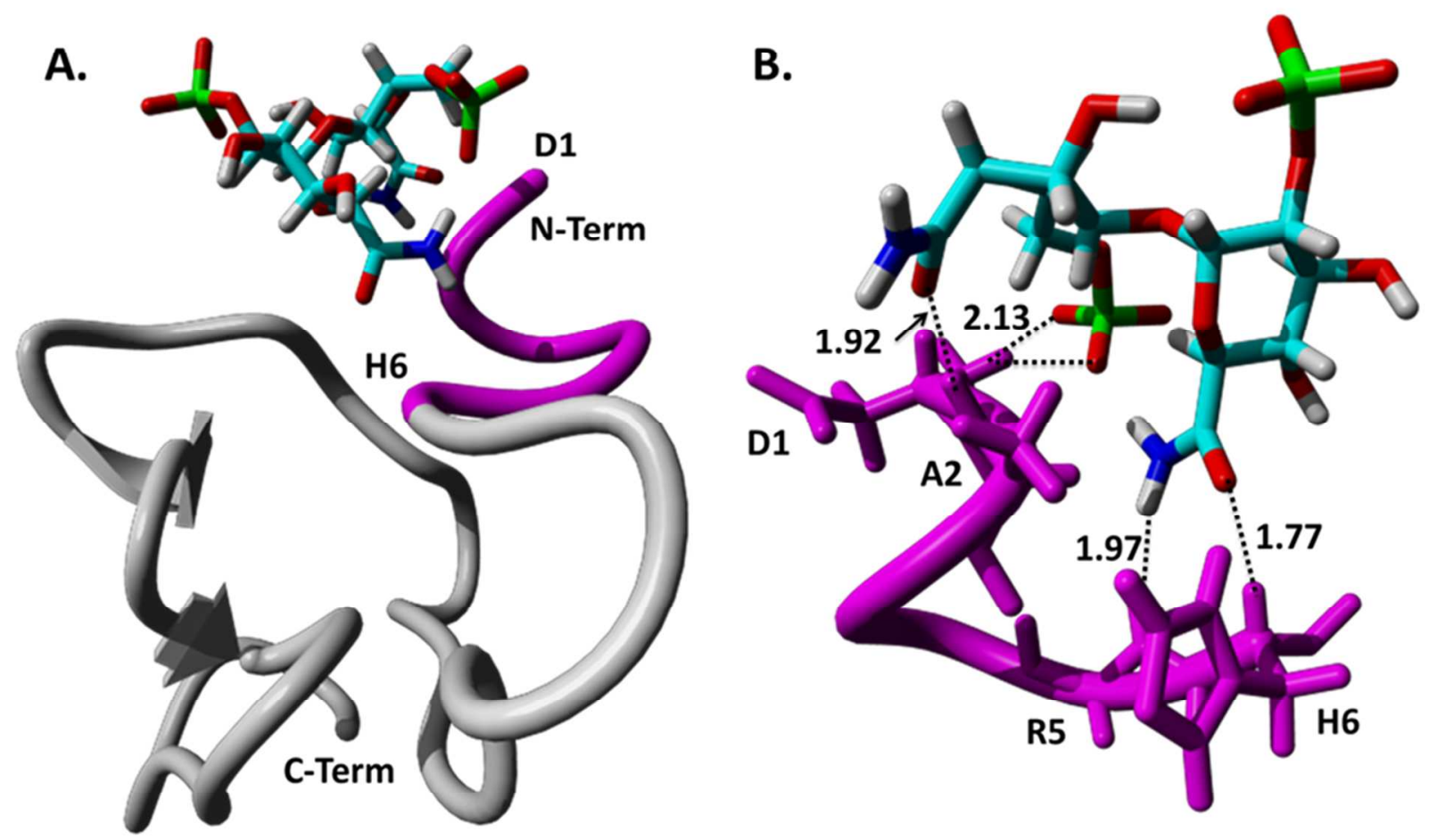

460 Figure 3. ADC (amide disaccharide) binding to the monomer form of the $A \beta_{40}$ peptide. (A)

461 zoomed out version showing the monomer binding pocket in magenta. (B) zoomed in view with

462 interacting residues and distances labeled. 


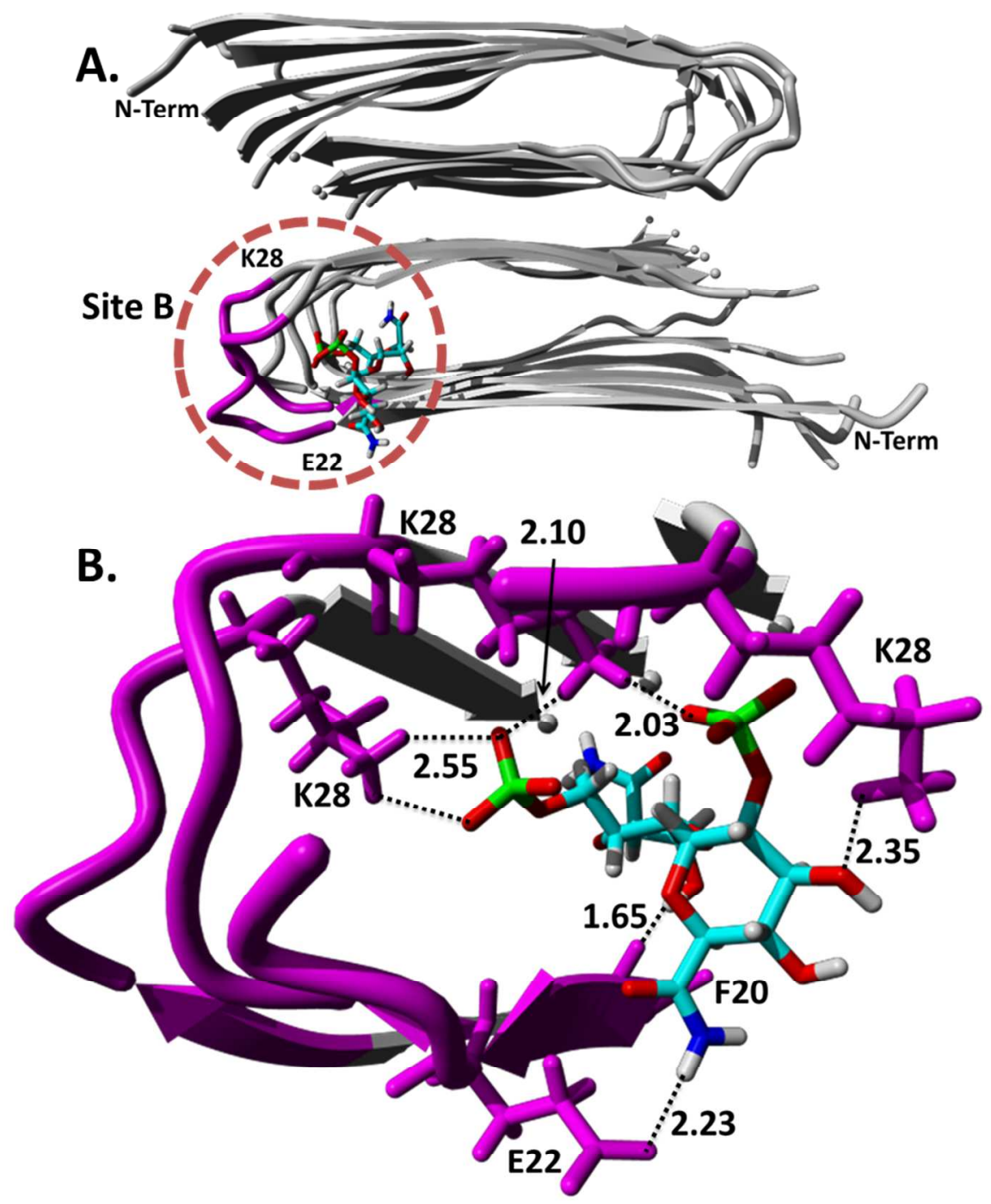

472 Figure 4. $\mathrm{ADC}$ (amide disaccharide) binding to the $\mathrm{A} \beta_{40}$ fibril. (A) zoomed out version showing

473 the fibril binding pocket shown in magenta. (B) zoomed in view with interacting residues and 474 distances labeled. 

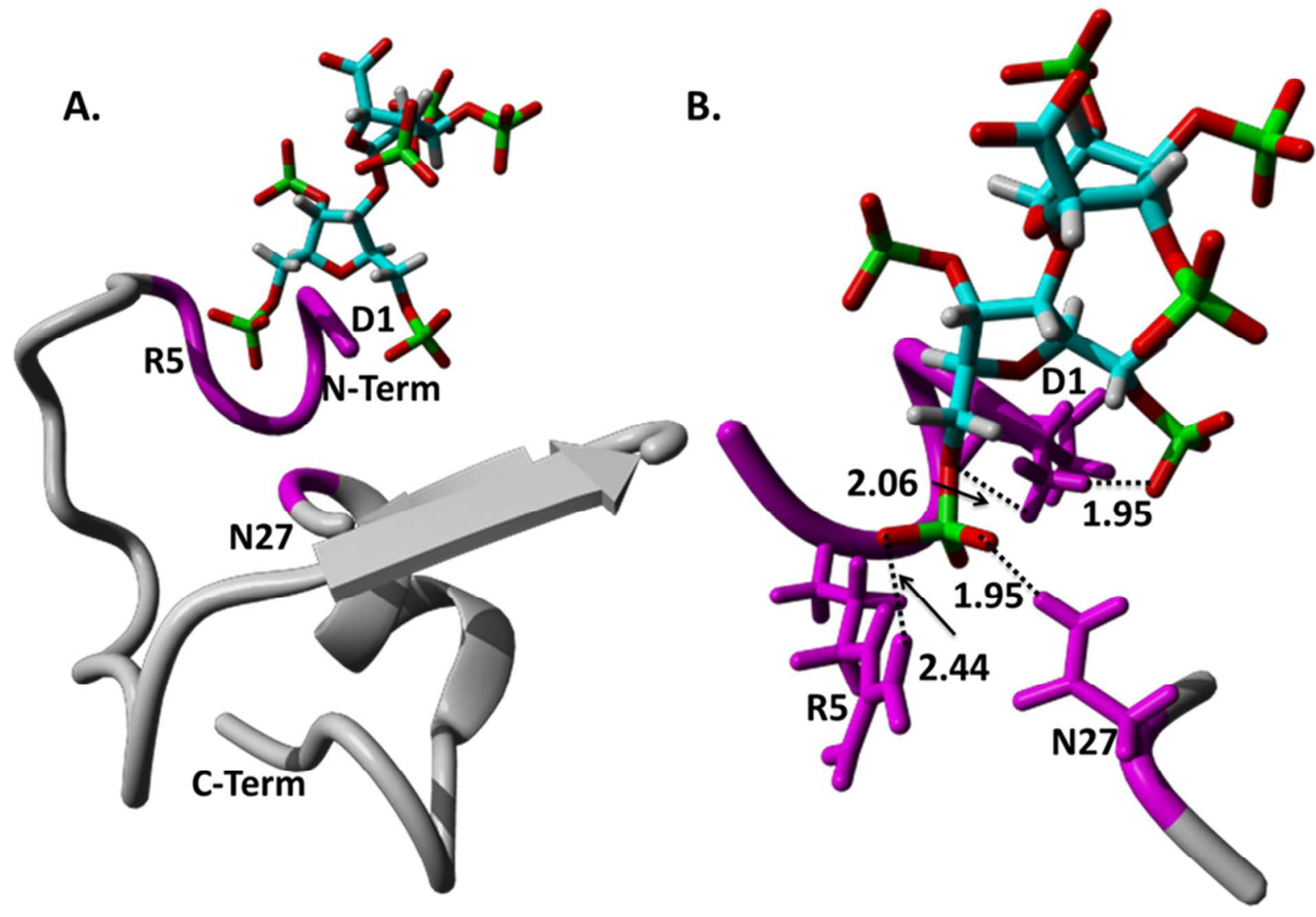

477

478 Figure 5. SDC (super-sulfated disaccharide) binding to the monomer form of the A $\beta_{40}$ peptide.

479 (A) zoomed out version showing the monomer binding pocket. (B) zoomed in view with 480 interacting residues and distances labeled. 


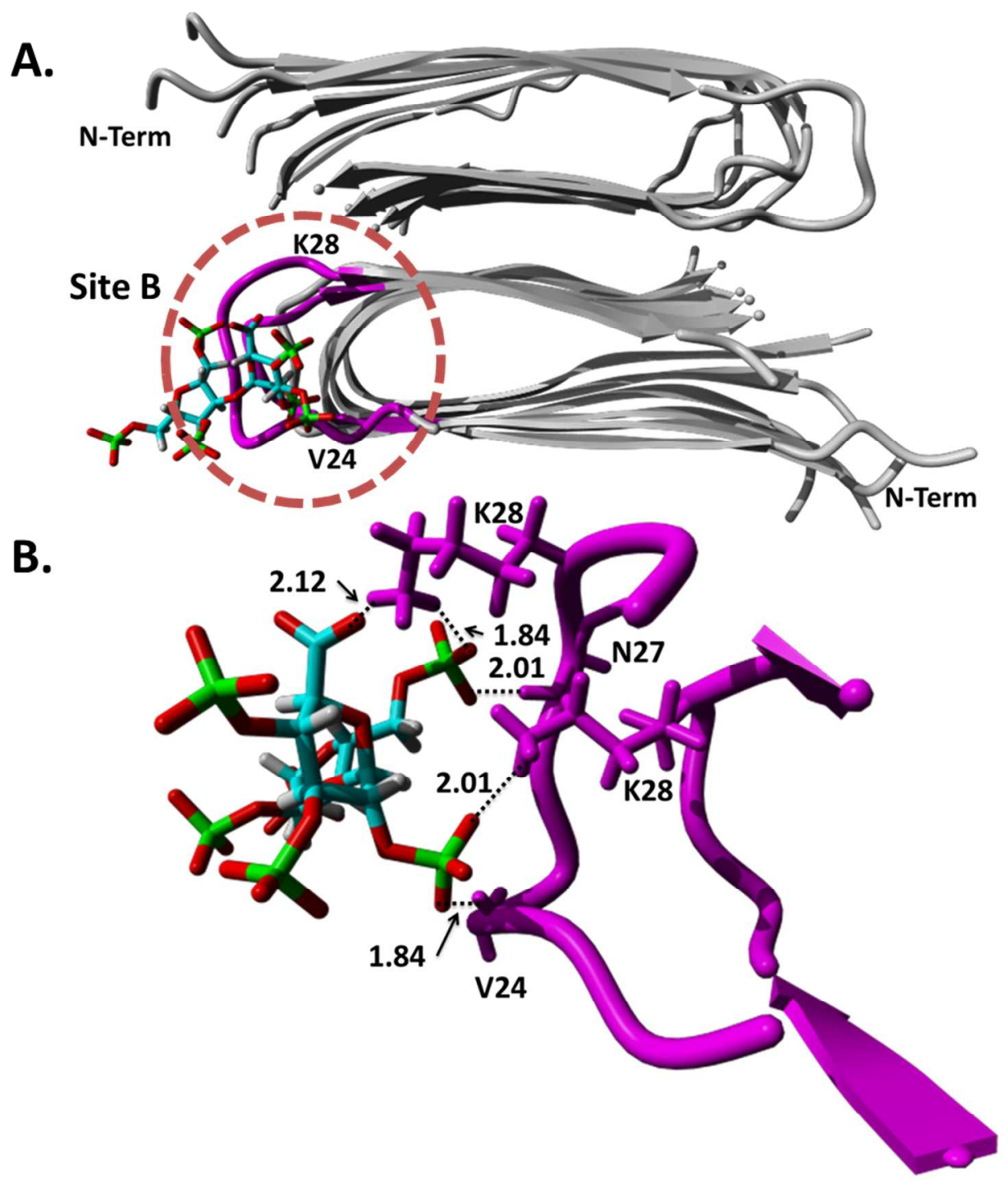

489 Figure 6. SDC (super-sulfated disaccharide) binding to the $A \beta_{40}$ fibril. (A) zoomed out version

490 showing the fibril binding pocket shown in magenta. (B) zoomed in view with interacting 491 residues and distances labeled. 


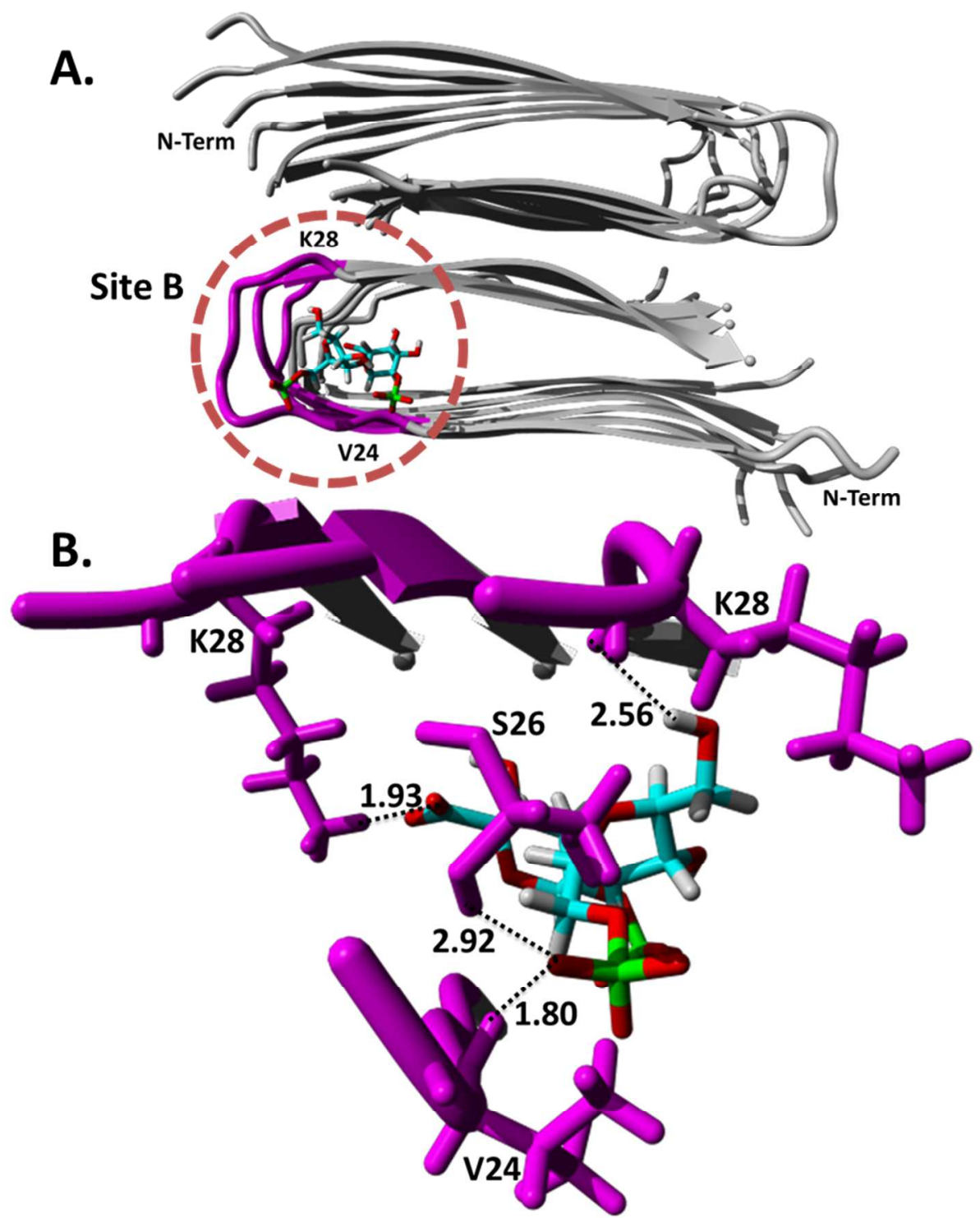

494 Figure 7. DC (heparin disaccharide) binding to the $A \beta_{40}$ fibril. (A) zoomed out version showing

495 the fibril binding pocket shown in magenta. (B) zoomed in view with interacting residues and 496 distances labeled. 


\begin{tabular}{lllllll}
\hline System & $\mathbf{E}_{\text {elec }}$ & $\boldsymbol{\Delta} \mathbf{G}_{\text {desol_A }}$ & $\Delta \mathbf{G}_{\text {desol_B }}$ & $\Delta \mathbf{G}_{\text {elec }}$ & $\Delta \mathbf{G}_{\text {nonpolar }}$ & $\Delta \mathbf{G}_{\text {binding }}$ \\
\hline ADC+monomer & -48.2 & 12.4 & 25.3 & -10.5 & -7.9 & -18.4 \\
ADC+Fibril & -81.0 & 34.8 & 39.7 & -6.5 & -15.9 & -22.4 \\
SDC+monomer & -74.2 & 36.4 & 26.0 & -11.8 & -8.4 & -20.2 \\
SDC+Fibril & -103.7 & 43.6 & 40.2 & -19.9 & -8.9 & -28.8 \\
DC+Fibril & -60.2 & 36.8 & 22.6 & -1.0 & -15.9 & -16.9 \\
& & & & & & \\
\hline
\end{tabular}

Table 1. Shows the relative binding energies calculated with separate energy contributions

502 determined. All energy values are shown in $\mathrm{kJ} / \mathrm{mol}$.

503

\begin{tabular}{ccc}
\hline Heparin Analogues & Site A & Site B \\
\hline ADC & $\mathrm{X}$ & $\mathrm{X}$ \\
SDC & $\mathrm{X}$ & $\mathrm{X}$ \\
DC & $\mathrm{X}$ & $\mathrm{X}$ \\
V1 & $\mathrm{X}$ & $\mathrm{O}$ \\
V2 & $\mathrm{O}$ & $\mathrm{O}$ \\
V3 & $\mathrm{O}$ & $\mathrm{O}$ \\
V4 & $\mathrm{O}$ & $\mathrm{O}$ \\
\hline
\end{tabular}

504 Table 2. List of successful heparin analogue binding to the $\mathrm{A} \beta_{40}$ fibril. The " $\mathrm{X}$ " represents

505 binding and the " $\mathrm{O}$ " represents no binding to that site. 